\title{
Chemical Vapor Deposition of Hexagonal Boron Nitride*
}

\author{
Satoru Suzuki ${ }^{\dagger}$ and Hiroki Hibino \\ NTT Basic Research Laboratories, NTT Corporation, \\ 3-1, Morinosato Wakamiya, Atsugi, Kanagawa 243-0198, Japan \\ (Received 27 December 2011; Accepted 5 March 2012; Published 27 April 2012)
}

\begin{abstract}
Nanometer-thick hexagonal boron nitride thin films were grown by thermal chemical vapor deposition on polycrystalline $\mathrm{Ni}, \mathrm{Co}$, and $\mathrm{Cu}$ substrates. A thicker and more regularly stacked film was grown on a Ni substrate, whereas a smaller film thickness and more turbostratic stacking or smaller domain size were observed on $\mathrm{Cu}$. Intermediate situations were observed on Co. The substrate material dependence strongly suggests that the substrate plays an important role in h-BN growth, like it does in graphene growth, although nitrogen is almost insoluble even in Ni. Grain boundaries may accommodate boron and nitrogen atoms at a growth temperature.

[DOI: $10.1380 /$ ejssnt.2012.133]
\end{abstract}

Keywords: Boron nitride; Chemical vapor deposition; Polycrystalline thin films

\section{INTRODUCTION}

Hexagonal boron nitride (h-BN) is a structural analog of graphene with an ideally small lattice mismatch $(2 \%)$. In remarkable contrast to the fact that graphene has no band gap, h-BN has a large band gap $(\sim 6 \mathrm{eV}[1])$ because of a certain degree of ionic character of the B-N bond. Thus, h-BN is often called "white graphene" recently $[2,3]$. Combining graphene and h-BN would lead to a wide variety of applications. In fact, it has been well demonstrated that the performance of a graphene device fabricated on a h-BN substrate is much better than that of a conventional device on $\mathrm{SiO}_{2}$ [4].

Thermal chemical vapor deposition (CVD) is a very powerful technique for large-area thin film growth with a low fabrication cost. Graphene growth by thermal CVD is now intensively studied, aiming at industrial applications of graphene. Thermal CVD growth of h-BN has also been reported in this several decades $[5,6]$. Even monolayer h$\mathrm{BN}$ has been synthesized by thermal decomposition of borazine $\left(\mathrm{B}_{3} \mathrm{~N}_{3} \mathrm{H}_{6}\right)$ in an ultrahigh vacuum chamber [7]. However, there have only been a few reports on growth of an atomically thin and well-crystallized h-BN film with a conventional CVD apparatus. Song et al. [8] synthesized h-BN films of 2-5 ML on a $\mathrm{Cu}$ substrate using ammonia borane $\left(\mathrm{NH}_{3}-\mathrm{BH}_{3}\right)$ as a feedstock. Their group also reported CVD growth of h-BN/graphene stacked layers on a $\mathrm{Cu}$ substrate [9]. Shi et al. reported growth of $\sim 5$ $50 \mathrm{~nm}$-thick h-BN on a Ni substrate using borazine [10].

In this paper, we report CVD growth of nanometerthick h-BN films on polycrystalline $\mathrm{Ni}$, $\mathrm{Co}$, and $\mathrm{Cu}$ substrates using ammonia borane as a feedstock. Much attention will be focused on the substrate material dependence of the structural properties.

\section{EXPERIMENTAL}

Ammonia borane was used as a $\mathrm{B}$ and $\mathrm{N}$ feedstock for the thermal CVD growth. A 300-nm-thick polycrystalline

\footnotetext{
* This paper was presented at the 6th International Symposium on Surface Science - Towards Nano, Bio and Green Innovation-, Tower Hall Funabori, Tokyo, Japan, December 11-15, 2011.

$\dagger$ Corresponding author: suzuki.satoru@lab.ntt.co.jp
}

$\mathrm{Ni}, \mathrm{Co}$, and $\mathrm{Cu}$ films were deposited on a $\mathrm{SiO}_{2} / \mathrm{Si}$ wafer by radio-frequency magnetron sputtering and used as substrates. The substrate was inserted into a tube furnace and heated up to a growth temperature of $800-990^{\circ} \mathrm{C}$ (the temperature was monitored by a thermocouple set just outside the tube) in $\mathrm{Ar} / \mathrm{H}_{2}$ atmosphere. When the temperature reached the growth temperature, the tube was once evacuated, and then ammonia borane vapor was introduced into the tube. The pressure during growth ranged from 50 to $1500 \mathrm{~Pa}$ and the growth time was 3 to $30 \mathrm{~min}$. After the growth, the ammonia borane vapor was quickly evacuated and the sample temperature was kept at the growth temperature in Ar atmosphere or a vacuum for $\sim 5$ min to avoid possible physisorption of precursor molecules on the sample surface. Then, the sample was cooled down naturally. An optical microscope image of a $\mathrm{Ni}$ sample after CVD is shown in Fig. 1. We can clearly observe Ni grains formed at the CVD temperature even after the CVD growth, because the CVD-grown film is highly transparent. The films were grown on such polycrystalline metal film consisting of grains of $1-10 \mu \mathrm{m}$ scale.

UV-visible light reflectance spectra were obtained using a JASCO V-650 spectrometer. Micro-Raman (Renishaw, Invia) measurements were performed at the excitation wavelength of $532 \mathrm{~nm}$. X-ray photoelectron spectra (XPS) were measured using a monochromatic Al K $\alpha$ source $(1486.6 \mathrm{eV})$. These measurements were carried out using as-grown films on the metal substrates. For optical

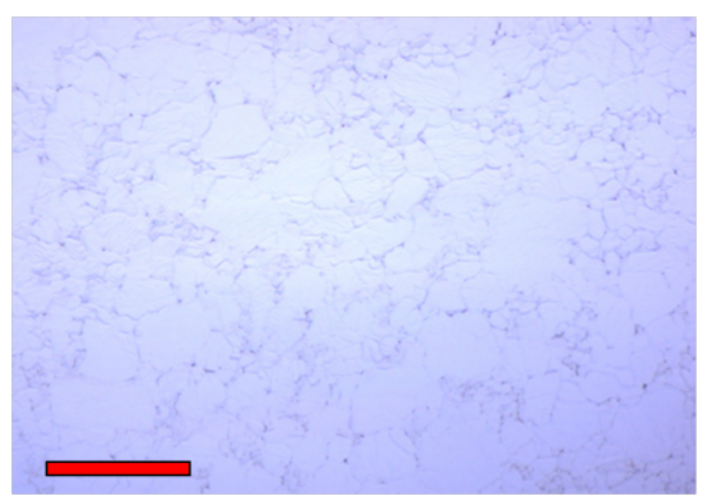

FIG. 1. Optical microscope image of a Ni substrate after CVD growth. Scale bar: $20 \mu \mathrm{m}$. 
microscope and atomic force microscope (AFM) observations, the films were transferred onto a $\mathrm{SiO}_{2} / \mathrm{Si}$ substrate. Protective poly(methyl methacrylate) (PMMA) film was spin-coated on the h-BN film, and the PMMA/hBN film was removed from the metal substrate by etching the metal in $\mathrm{FeCl}_{3}$ solution of $1 \mathrm{M}$. The PMMA/hBN film was rinsed in deionized water and transferred onto another $\mathrm{SiO}_{2} / \mathrm{Si}$ substrate. Finally, the PMMA film was removed by either immersion in acetone or heating at $400^{\circ} \mathrm{C}$ in $\mathrm{H}_{2}$ atmosphere. Similarly, for transmission electron microscopy (TEM) and electron energy loss spectroscopy (EELS) measurements, the h-BN film was transferred onto a TEM grid. The TEM (JEOL JEM-2100F) was operated at $200 \mathrm{kV}$. For electric measurements, the film was transferred onto a $\mathrm{SiO}_{2}(285 \mathrm{~nm}) / \mathrm{Si}$ (heavily doped) substrate. A field effect transistor device (channel length and width of $\sim 50 \mu \mathrm{m}$ and $\sim 2.5 \mu \mathrm{m}$ ) was fabricated on a $\mathrm{SiO}_{2}(285 \mathrm{~nm}) / \mathrm{Si}$ (heavily doped) substrate using photolithography, oxygen plasma etching, electron beam deposition of $\mathrm{Au} / \mathrm{Cr}$ electrodes, and lift-off techniques. The substrate worked as a back-gate. Electric measurements were carried out at room temperature in a probing station evacuated by a turbo molecular pump $\left(\sim 10^{-4} \mathrm{~Pa}\right)$.

\section{RESULTS}

The compositions of the films were analyzed by corelevel XPS. Figure 2(a) shows wide range XPS of films grown on $\mathrm{Ni}, \mathrm{Co}$, and $\mathrm{Cu}$ substrates and of graphene grown on $\mathrm{Ni}$ from spin-coated polyaniline [11] for reference. The $\mathrm{B} 1 s$ and $\mathrm{N} 1 s$ peaks are clearly observed from the films. The $\mathrm{C} 1 s$ signal should be at least partly due to surface contamination, because the samples were exposed to air prior to the measurements. We think that the $\mathrm{O} 1 s$ signal is mainly due to molecules adsorbed on the surface and edge of the grains and that the $\mathrm{O} 1 s$ peak intensity would be significantly reduced by annealing in a vacuum, as demonstrated in a previous report [12]. Unfortunately, however, annealing in a vacuum prior to the XPS measurements was not possible due to an apparatusrelated restriction of the XPS system. The $\mathrm{O} 1 s$ peak was also observed for the graphene film. The relative compositions of $\mathrm{B}, \mathrm{C}$, and $\mathrm{N}$ atoms did not strongly depend on the substrate and were determined to be $\mathrm{B}_{0.35} \mathrm{C}_{0.25} \mathrm{~N}_{0.40}$ (on $\mathrm{Ni}$ ), $\mathrm{B}_{0.38} \mathrm{C}_{0.22} \mathrm{~N}_{0.40}$ (on $\mathrm{Co}$ ), and $\mathrm{B}_{0.38} \mathrm{C}_{0.27} \mathrm{~N}_{0.35}$ (on $\mathrm{Cu}$ ). The $\mathrm{B}$ and $\mathrm{N}$ contents were approximately the same. The B $1 s$ and $\mathrm{N} 1 s$ spectra are shown in Figs. 2(b) and (c). Typical binding energy positions [13-17] of some related chemical bonds are denoted in the figures. The B $1 s$ and $\mathrm{N} 1 s$ peak positions are close to those of h-BN regardless of the substrate, and are observed at around 190.8 and $398.5 \mathrm{eV}$, respectively. The binding energy difference is about $207.7 \mathrm{eV}$ for all cases, and this value is almost consistent with those of previous reports $(207.5-208.0 \mathrm{eV}$ $[13,15-17])$. Although the B and N $1 s$ spectra are slightly asymmetric on Co, they show similar shapes. Considering that h-BN has a large band gap, the asymmetry may be attributed to variations of local Fermi energy positions caused by defects or impurities. On $\mathrm{Cu}$, only the $\mathrm{B} 1 \mathrm{~s}$ spectrum has a tail at the high binding energy side, and this may be due to an oxide component caused by a small
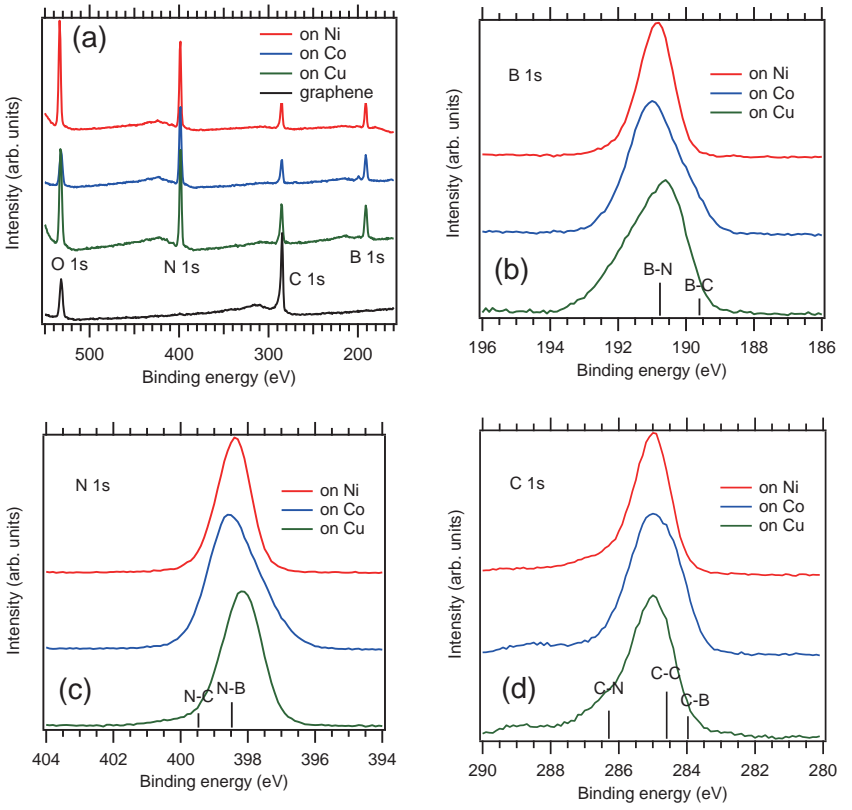

FIG. 2. (a) Wide-range, (b) B $1 s$, (c) N $1 s$, and (d) C $1 s$ XPS of the films grown on $\mathrm{Ni}, \mathrm{Co}$, and $\mathrm{Cu}$. In (a), a spectrum of graphene is shown for reference. In (b), (c), and (d) typical binding energy positions are denoted.

number of excess B atoms. Fig. 2(d) shows the C $1 s$ spectra. On Co, the spectrum is broad, and one may think that there are considerable contributions from $\mathrm{C}-\mathrm{B}$ and $\mathrm{C}-\mathrm{N}$ bonds. However, an $\mathrm{N}-\mathrm{C}$ component is not clearly observed in the $\mathrm{N} 1 s$ spectrum. On $\mathrm{Cu}$, although the high-binding-energy component looks like a $\mathrm{C}-\mathrm{N}$ bond, the corresponding component is not clearly observed in the $\mathrm{N} 1 s$ spectrum, either. We therefore think that there are not large $\mathrm{C}-\mathrm{B}$ and $\mathrm{C}-\mathrm{N}$ components and that the $\mathrm{C}$ spectra are at least mainly from surface contamination on the grown film. However, we do not fully exclude the possibility that $\mathrm{C}$ of several at

Wide-range EEL spectra of films grown on Ni, Co, and $\mathrm{Cu}$ are shown in Fig. 3(a). For reference, spectra of h$\mathrm{BN}$ and $\mathrm{B}_{2} \mathrm{O}_{3}$ in powder forms are also shown. The $\mathrm{B}-K$, and N-K EELS are commonly observed from the films and the intensity ratio is similar to the reference sample h-BN. Figure 3(b) shows the B- $K$ near-edge structures of the films and reference samples. All the spectra of the films are almost identical to that of h-BN. The peaks at 192 and $200 \mathrm{eV}$ are assigned to $1 s \rightarrow \pi^{*}$ and $1 s \rightarrow \sigma^{*}$ transitions and characteristic of h-BN [18]. A peak at $\sim 192 \mathrm{eV}$ is also observed for $\mathrm{B}_{2} \mathrm{O}_{3}$; however, the higher energy spectrum is distinctly different from the others. Thus, we did not observe any clear indication of incorporation of $\mathrm{B}_{2} \mathrm{O}_{3}$ in the films, including on $\mathrm{Cu}$. The $\mathrm{N}-K$ near-edge structures are shown in Fig. 3(c). The transitions to the $\pi^{*}$ and $\sigma^{*}$ are also observed at $\sim 403$ and $411 \mathrm{eV}$, due to hybridization of $\mathrm{B}$ and $\mathrm{N}$ atomic orbitals in the unoccupied states. All the spectra of the films are consistent with that of h-BN, again.

The existence of a h-BN film on a metal substrate can be easily checked by reflectance spectroscopy in the UV region [19]. The reflectance spectra of films grown on $\mathrm{Ni}, \mathrm{Co}$, and $\mathrm{Cu}$ are shown in Fig. 4. The spectra at low energies are mainly from the metal substrates under the 

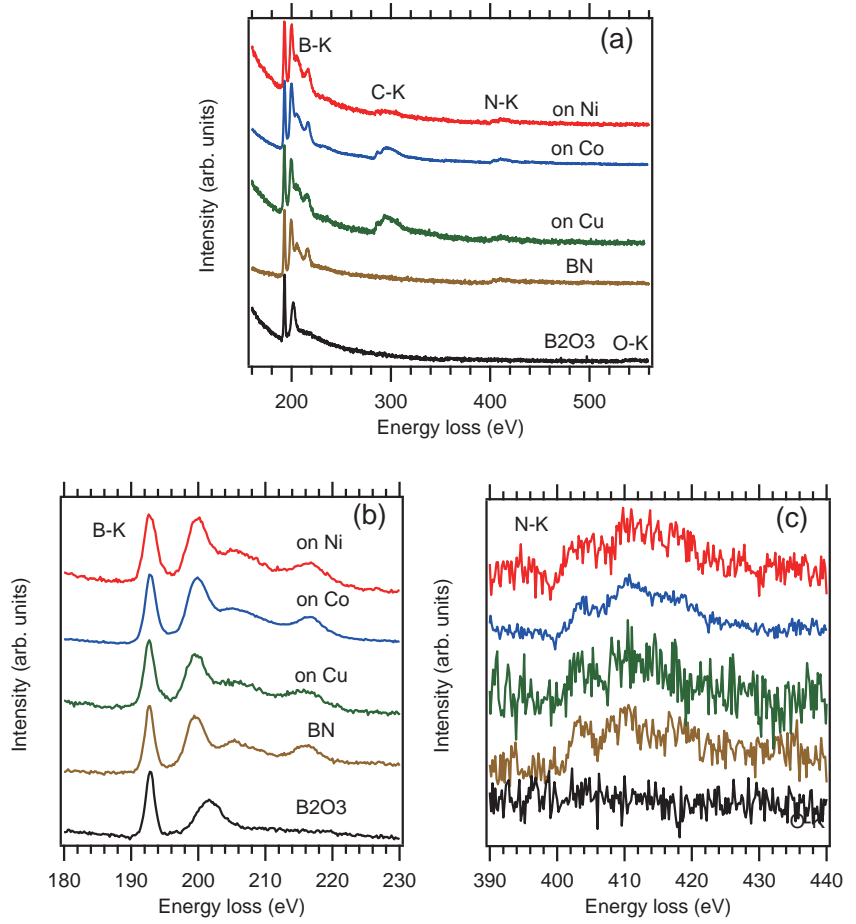

FIG. 3. (a) Wide-range, (b) B- $K$, and (c) N-K EELS of films grown on $\mathrm{Ni}, \mathrm{Co}$, and $\mathrm{Cu}$. Spectra of $\mathrm{BN}$ and $\mathrm{B}_{2} \mathrm{O}_{3}$ are also shown for reference.

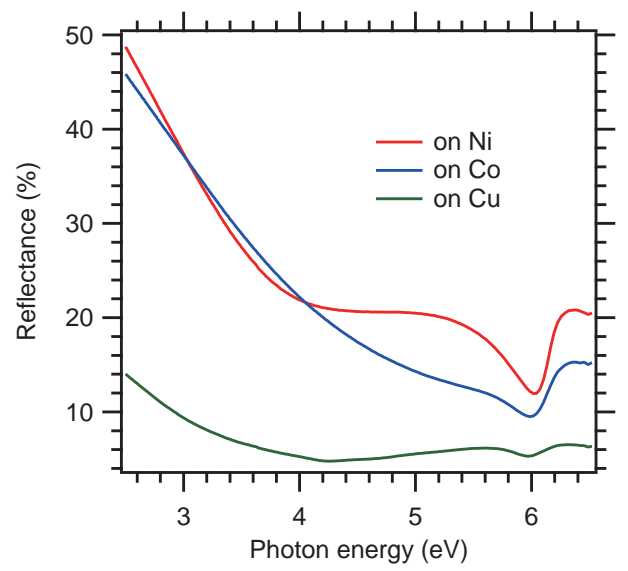

FIG. 4. Reflectance spectra of films grown on $\mathrm{Ni}$, Co, and $\mathrm{Cu}$.

CVD-grown films. The spectra commonly show a peak at $6.3 \mathrm{eV}(\lambda \sim 195 \mathrm{~nm})$, which is indicative of h-BN $[20,21]$. The peak height can be an indicator of relative film thickness. The three films were grown under the same conditions $\left(950^{\circ} \mathrm{C}\right.$ growth temperature, $1000 \mathrm{~Pa}$ vapor pressure, 3 min growth time), except for the differences in the substrate materials. The thicknesses on $\mathrm{Ni}$ and $\mathrm{Co}$ are close, and that on $\mathrm{Cu}$ is about one-fifth of those. We will further address this issue below.

The Raman spectra of relatively thick $(\sim 10 \mathrm{~nm}$ or larger) films grown on a $\mathrm{Ni}$ and Co substrate are shown in Fig. 5. A single peak was observed at about $1367 \mathrm{~cm}^{-1}$. This peak can be assigned to the $\mathrm{E}_{2 g}$ tangential mode of h-BN [22] and thus clearly indicates the formation of h-BN. The slight peak shift to the lower wavenumber side observed on Co was due to a laser-induced temperature increase (the laser power density was $\sim 10$ times larger). The line widths are 28 and $36 \mathrm{~cm}^{-1}$ on $\mathrm{Ni}$ and

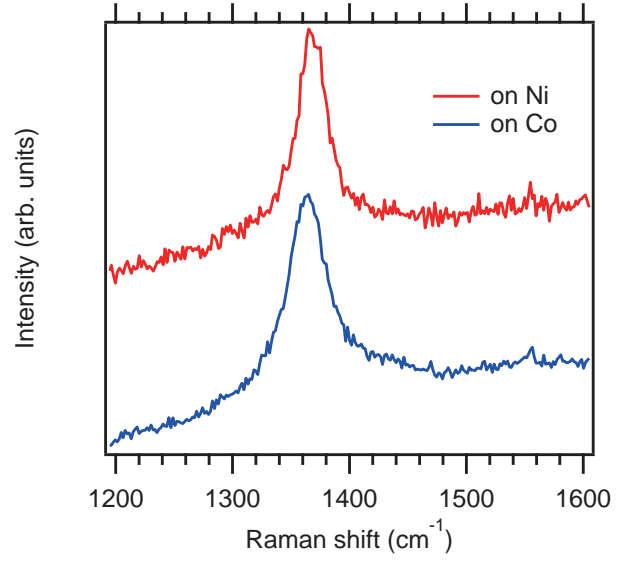

FIG. 5. Raman spectra of a film grown on a Ni and Co substrate.

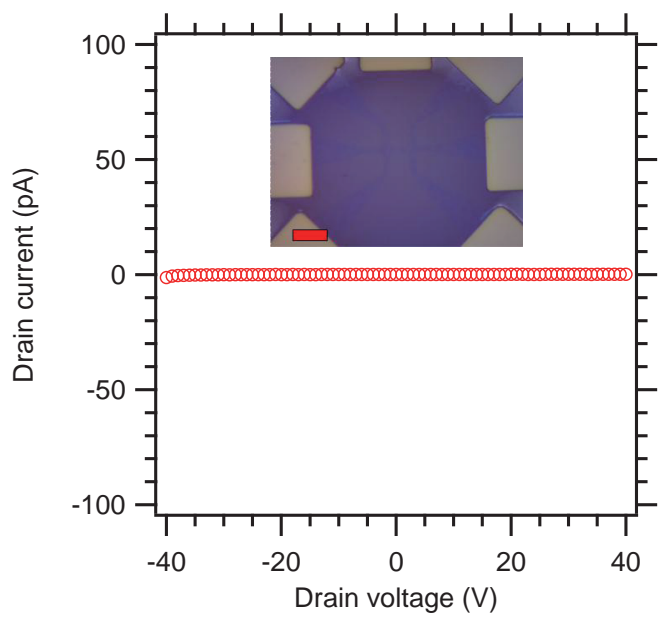

FIG. 6. Current-voltage characteristics of a h-BN device obtained at the gate voltage of $0 \mathrm{~V}$. The inset shows an optical microscope image of the device. Scale bar: $10 \mu \mathrm{m}$.

Co, respectively. Although these values are much larger than those of single crystalline h-BN grown by the highpressure/high-temperature method $\left(9.1 \mathrm{~cm}^{-1}\right)[6]$ and by metalorganic vapor phase exitaxy $\left(\sim 13 \mathrm{~cm}^{-1}\right)$ [23], it is comparable to those of BN nanotubes synthesized at relatively low temperatures of $1200\left(27 \mathrm{~cm}^{-1}\right)$ and $1050^{\circ} \mathrm{C}$ $\left(38 \mathrm{~cm}^{-1}\right)$ [24]. No indication of graphene formation $\left(\sim 1580 \mathrm{~cm}^{-1}\right)$ is seen in Fig. 5 . Unfortunately, we have not observed distinct Raman signal from a h-BN film grown on $\mathrm{Cu}$, probably because the thickness is too small (attempts at growing a thick film on $\mathrm{Cu}$ often resulted in discretization of the $\mathrm{Cu}$ film).

All the spectroscopic results shown in Figs. 2-5 unambiguously show that it is h-BN films that were grown on the metal substrates.

Figure 6 shows the current-voltage characteristics of a device obtained at a back-gate voltage of $0 \mathrm{~V}$. Almost no current is observed despite the large drain voltage of up to $\pm 40 \mathrm{~V}$. We could not observe any current in a wide gate voltage range of -40 to $40 \mathrm{~V}$. These results show the h-BN film is highly insulating. This is reasonable when we consider that the band gap of h-BN is very large $(\sim 6 \mathrm{eV})$. Semiconducting [3] or even metallic [2] nature at an edge of h-BN has been reported theoretically. In fact, edge conduction has been experimentally reported 


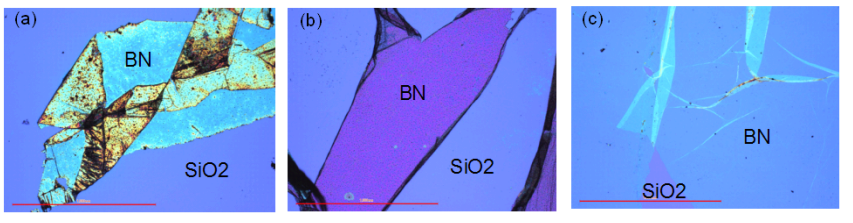

FIG. 7. Low-magnification optical microscope images of BN films grown on (a) Ni, (b), Co, and (c) Cu after transfer onto $\mathrm{SiO}_{2} / \mathrm{Si}$ substrates. Scale bars: $1 \mathrm{~mm}$.
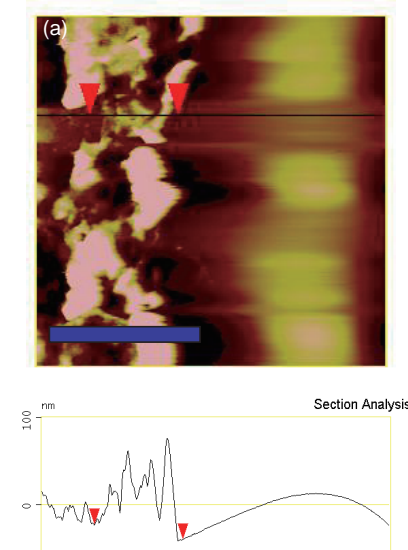

(b)

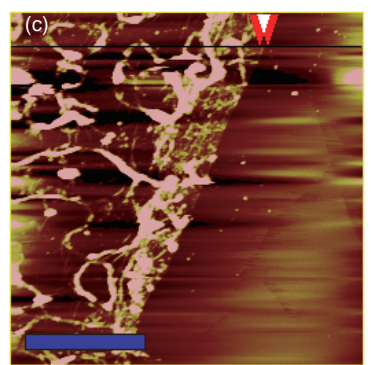

Section Analysis

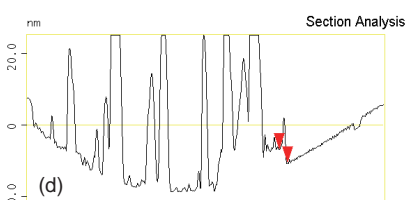

FIG. 8. (a) AFM image of a h-BN film grown on Ni after transfer onto a $\mathrm{SiO}_{2} / \mathrm{Si}$ substrate. (b) Height profile along the line in (a). (c) AFM image of a h-BN film grown on $\mathrm{Cu}$ after transfer onto a $\mathrm{SiO}_{2} / \mathrm{Si}$ substrate. (d) Height profile along the line in (c).

for a BN nanoribbon formed by unwrapping a multiwall $\mathrm{BN}$ nanotube [2]. Although the detailed reason for the discrepancy is not clear at present, it may originate in the differences in the detailed edge structures. Our result is consistent with a previous report in which no conduction was observed from a CVD-grown h-BN film [8].

Hereafter, we mainly focus on the structural properties and their substrate material dependence. Lowmagnification optical microscope images of h-BN films after the films had been transferred onto $\mathrm{SiO}_{2}(285 \mathrm{~nm}) / \mathrm{Si}$ substrates are shown in Fig. 7. The relatively thick films were intentionally grown on (a) $\mathrm{Ni}$, (b) $\mathrm{Co}$, and (c) $\mathrm{Cu}$ at the same conditions $\left(950^{\circ} \mathrm{C}, 1500 \mathrm{~Pa}, 30 \mathrm{~min}\right)$. The observed folding, rolling, and corrugation were formed during the transfer process. The film grown on $\mathrm{Cu}$ shows weaker contrast, indicating that it is thinner. AFM images and height profiles obtained from the h-BN films shown in Figs. 7(a) and (c) are shown in Fig. 8. The ribbon-like feature seen in Fig. 8(c) is corrugation formed around holes in the $\mathrm{Cu}$ film (at a high temperature, holes are often formed in $\mathrm{Cu}$ films). Although precise height determination was difficult due to the corrugation of the transferred film, the thickness of the film grown on $\mathrm{Ni}$ was estimated to be $\sim 20 \mathrm{~nm}$ or larger and that the film grown on $\mathrm{Cu}$ to be $\sim 4 \mathrm{~nm}$. These results show that the film thickness strongly depends on the substrate material and that a thinner film is obtained on $\mathrm{Cu}$. They are consistent with the reflection spectroscopy results shown in Fig. 4.
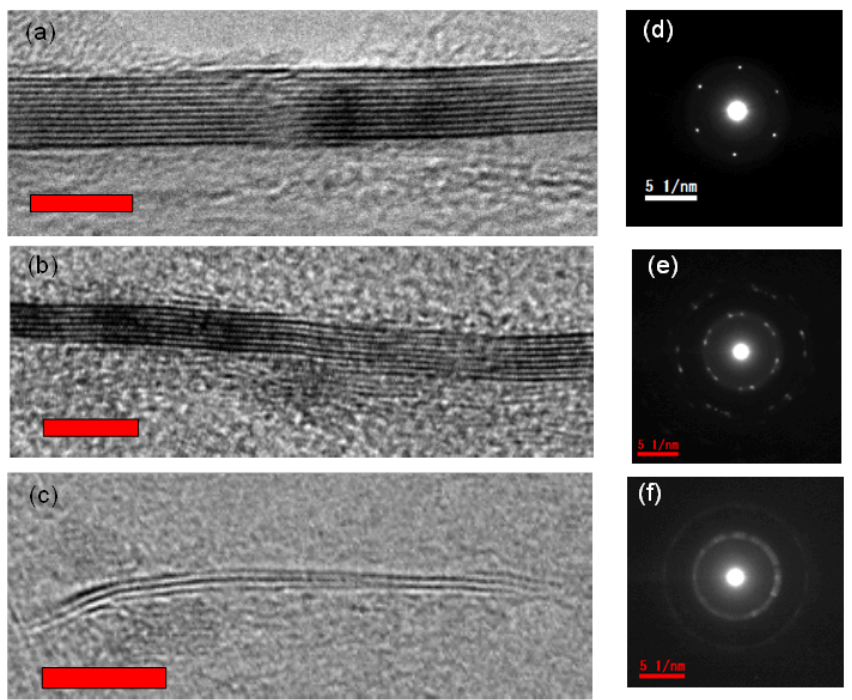

FIG. 9. (a)-(c) TEM image of h-BN films grown on (a) Ni, (b) $\mathrm{Co}$, and (c) Cu. (d)-(f) SAED patterns of h-BN films grown on (d) Ni, (e) Co, and (f) Cu. In (a)-(c), scale bars: $5 \mathrm{~nm}$.

Cross-sectional TEM images of films grown on (a) $\mathrm{Ni}$, (b) Co, and (c) $\mathrm{Cu}$ are shown in Fig. 9. These images were obtained from corrugated parts of the films. Layered structures are clearly observed for all the substrates. The layer-repeat distance was evaluated to be $0.33 \pm 0.03 \mathrm{~nm}$, which is consistent with that of h-BN (0.333 nm [25]). The films grown on $\mathrm{Ni}$ and $\mathrm{Co}$ were obtained at the same growth condition $\left(900^{\circ} \mathrm{C}, 70 \mathrm{~Pa}, 7 \mathrm{~min}\right)$. About 12 and 8 layers are seen in Figs. 9(a) and (b). The numbers of layers observed from the films ranged from 7 to 12 and 5 to 8 for $\mathrm{Ni}$ and $\mathrm{Co}$, respectively. The average thickness on Co is close to or slightly smaller than that on Ni. We can also grow few-layer film as shown in Fig. 9(c). We observed 2 to 6 layers from the film. In this case, the substrate was $\mathrm{Cu}$ and growth conditions were $990^{\circ} \mathrm{C}$, $1000 \mathrm{~Pa}$, and $3 \mathrm{~min}$. Reflection spectra (not shown, but similar to those in Fig. 4) revealed that thicker films were grown for $\mathrm{Ni}$ and $\mathrm{Co}$ again under this condition.

We also found that the stacking or domain structure depends on the substrate material. Selected area $(\sim 150 \mathrm{~nm})$ electron diffraction patterns obtained from the films in Fig. 9(a)-(c) are shown in Figs. 9(d)-(f). Six-fold symmetry is observed for all substrates. A single set of spots was often observed from the film grown on $\mathrm{Ni}$, as shown in Fig. 9(d), although the number of layers is the largest. This indicates that the layers are stacked quite regularly. We can expect that $\mathrm{B}$ and $\mathrm{N}$ atoms are aligned alternately in the c direction, as in bulk h-BN [25]. A few sets of spots were observed from the film grown on Co. Despite its having the smallest number of layers, the film grown on $\mathrm{Cu}$ shows a ring-like pattern, indicating that the stacking is highly turbostratic or the film consists of domains much smaller than the beam size of $150 \mathrm{~nm}$. Thus, stacking disorder increases or domain size decreases in the order of a $\mathrm{Ni}, \mathrm{Co}$, and $\mathrm{Cu}$ substrate. 


\section{DISCUSSION}

As shown above, substrate material dependence of film thickness and stacking/domain structure was observed for $\mathrm{Ni}, \mathrm{Co}$, and $\mathrm{Cu}$. A smaller thickness and more turbostratic stacking/smaller domains were observed for a $\mathrm{Cu}$ substrate than for $\mathrm{Ni}$ and Co substrates at the same growth condition. Similarly, a thick (up to $\sim 50 \mathrm{~nm}$ ) and regularly stacked film on $\mathrm{Ni}$ [10] and a thin (2-5 ML) and turbostratically stacked film on $\mathrm{Cu}$ [8] were also observed in previous studies on the CVD growth of h-BN, although feedstocks used in the two studies were different. These strongly suggest that the substrate has an essentially important role for the CVD growth of a hBN film. The metal surface has a catalytic function for decomposition of the feedstock molecule and the degree of the catalytic function would depend on the material. However, the differences in the catalytic function do not explain the results because the metal surface was entirely covered by few-layer or multilayer h-BN regardless of the substrate material in this study. Similar substrate dependence of thickness and stacking structure have been observed for growth of graphene on a metal substrate. On Ni, a larger thickness and more regular stacking have been observed [26,27], whereas a smaller thickness and turbostratic stacking have been observed on a $\mathrm{Cu}$ substrate [28]. In the case of graphene, the substrate dependence has been considered to be due to differences in carbon solubility and to consequent different growth mechanisms. On Ni, which has high carbon solubility at growth temperatures $\left(\sim 0.9\right.$ at. $\%$ at $\left.900^{\circ} \mathrm{C}\right)$, graphene growth by CVD occurs mainly by segregation or precipitation during cooling [29]. This tends to result in the growth of thick graphene film and probably regular stacking. On the other hand, a graphene film is grown by surface absorption on $\mathrm{Cu}$ [27], which has a much lower carbon solubility ( 0.005-0.04 at.\% at $\left.1084^{\circ} \mathrm{C}[30]\right)$. Consequently, a thinner and turbostratic stacked film is formed. Growth of h-BN on $\mathrm{Cu}$ may also be dominated by surface adsorption. However, in the case of h-BN growth on $\mathrm{Ni}$, it does not seem that the above scenario can simply be applied. Although Ni has a considerably high B solubility $\left(0.3 \%\right.$ at $\left.1085^{\circ} \mathrm{C}[31]\right), \mathrm{N}$ solubility has been reported to be almost zero in molten $\mathrm{Ni}[31]$ and $\sim 0.005$ at.\% even at an extremely high temperature of $1600^{\circ} \mathrm{C}[32]$. At this stage, the concrete reason for the substrate dependence is unclear. However, the substrate dependence similar to that in graphene growth suggests that the substrate plays an important role for providing the surface with B and $\mathrm{N}$ atoms at least at the initial stage of the CVD growth. One possibility may be that $\mathrm{B}$ and $\mathrm{N}$ atoms are accommodated in the grain boundaries of polycrystalline Ni and Co substrates at the CVD temperatures, and they segregate and form h-BN at lower temperatures. In fact, CVD growth of graphene at a $\mathrm{Cu} / \mathrm{SiO}_{2}$ interface through the $\mathrm{Cu}$ film has been reported [33]. In this case, carbon atoms are believed to diffuse from the $\mathrm{Cu}$ surface to the $\mathrm{Cu} / \mathrm{SiO}_{2}$ interface through grain boundaries.

\section{CONCLUSIONS}

Nanometer-thick thin films were grown on Ni, Co, and $\mathrm{Cu}$ substrates by thermal CVD using ammonia borane as a feedstock. XPS, EELS, reflection spectroscopy, Raman spectroscopy, and TEM observation revealed that h-BN is grown regardless of the substrate. A thicker and thinner film was grown on $\mathrm{Ni}$ and $\mathrm{Cu}$. More regular stacking was observed on $\mathrm{Ni}$ and more turbostratic or smaller domain size was observed on $\mathrm{Cu}$. This substrate dependence is basically similar to that observed in graphene growth, and suggests an important role of the substrate for h-BN growth. However, the segregation or precipitation mechanism proposed for graphene growth on $\mathrm{Ni}$ can not be simply applied to h-BN growth, because nitrogen is almost insoluble in $\mathrm{Ni}$. We think that $\mathrm{B}$ and $\mathrm{N}$ atoms are accommodated at the grain boundaries of the polycrystalline metal substrates.

\section{ACKNOWLEDGMENTS}

The authors thank H. Ikeda for TEM and EELS measurements, H. Ando for XPS measurements, and M. Ueki for device fabrication. They also thank Dr. Y. Kobayashi for the use of the UV-visible reflectance spectroscopy apparatus.
[1] K. Watanabe, T. Taniguchi, and H. Kanda, Nature Mater. 3, 404 (2004).

[2] H. Zeng, C. Zhi, Z. Zhang, X. Wei, X. Wang, W. Guo, Y. Bando, and D. Golberg, Nano. Lett. 10, 5049 (2010).

[3] Y. Liu, S. Bhowmick, and B. I. Yakobson, Nano. Lett. 11, 3113 (2011).

[4] C. R. Dean, A. F. Young, I. Meric, C. Lee, L. Wang, S. Sorgenfrei, K. Watanabe, T. Taniguchi, P. Kim, K. L. Shepard, and J. Hone, Nature Nanotechnol. 5, 722 (2010).

[5] M. Rand and J. Roberts, J. Electrochem. Soc. 115, 423 (1968), and references therein.

[6] O. Tsuda, K. Watanabe, and T. Taniguchi, Jpn. J. Appl. Phys. 46, L287 (2007).

[7] A. Nagashima, N. Tejima, Y. Gamou, T. Kawai, and C. Oshima, Surf. Sci. 357-358, 307 (1996).
[8] L. Song, L. Ci, H. Lu, P. B. Sorokin, C. Jin, J. Ni, A. G. Kvashnin, D. G. Kvashnin, J. Lou, B. I. Yakobson, and P. M. Ajayan, Nano Lett. 10, 3209 (2010).

[9] Z. Liu, L. Song, S. Zhao, J. Huang, L. Ma, J. Zhang, J. Lou, and P. M. Ajayan, Nano Lett. 11, 2032 (2011).

[10] Y. Shi, C. Hamsen, X. Jia, K. Kim, A. Reina, M. Hofmann, A. L. Hsu, K. Zhang, H. Li, Z. Juang, M. S. Dresselhaus, L. Li, and J. Kong, Nano Lett. 10, 4134 (2010).

[11] S. Suzuki, Y. Takei, K. Furukawa, G. Webber, S. Tanabe, and H. Hibino, Jpn. J. Appl. Phys. 50 (2012), in press.

[12] D. Wei, Y. Liu, Y. Wang, H. Zhang, L. Huang, and G. Yu, Nano Lett. 9, 1752 (2009).

[13] M.O. Watanabe, S. Itoh, K. Mizushima, and T. Sasaki, Appl. Phys. Lett. 68, 2962 (1996).

[14] M. A. Mannnan, Y. Baba, T. Kida, M. Nagano, I. Shimoyama, N. Hirao, and H. Noguchi, Thin Solid Films 519, 
1780 (2011).

[15] S. Nakao, T. Sonoda, K. Tsugawa, J. Choi, and T. Kato, Vacuum 84, 642 (2009).

[16] E. Bengu, M.F. Genisel, O. Gulseren, and R. Ovali, Thin Solid Films 518, 1459 (2009).

[17] S. Kim, J. Park, H. Choi, J. Ahn, J. Hou, and J. Kang, J. Am. Chem. Soc. 129, 1705 (2007).

[18] A. B. Preobrajenski, A. S. Vinogardov, and N. Martensson, Surf. Sci. 582, 21 (2005).

[19] S. Suzuki and H. Hibino, Mater. Sci. Eng. B 177, 233 (2012).

[20] D. M. Hoffman, G. L. Doll, and P. C. Eklund, Phys. Rev. B 30, 6051 (1984).

[21] A. Chayahara, H. Yokoyama, T. Imura, Y. Osaka, and M. Fujisawa, Jpn. J. Appl. Phys. 27, 440 (1988).

[22] S. Reich, A. C. Ferrari, R. Arenal, A. Loiseau, I. Bello, and J. Robsrtson, Phys. Rev. B 71, 205201 (2005).

[23] Y. Kobayashi and T. Akasaka, J. Cryst. Growth 310, 5044 (2008).

[24] S. Bae, H. Seo, J. Park, Y. Choi, J. Park, and S. Lee, Chem. Phys. Lett. 374, 534 (2003).
[25] D. Golberg, Y. Bando, Y. Huang, T. Terao, M. Mitome, C. Tang, and C. Zhi, ACS Nano 4, 2979 (2010).

[26] A. Johansson, J. Lu, and J. Carlsson, Thin Solid Films 252, 19 (1994).

[27] A. Reina, X. Jia, J. Ho, D. Nezich, H. Son, V. Bulovic, M. S. Dresselhaus, and J. Kong, Nano Lett. 9, 30 (2009).

[28] T. P. Ong, F. Xiong, R. P. H. Chang, and C. W. J. White, J. Mater. Res. 7, 2429 (1992).

[29] X. Li, W. Cai, L. Colombo, and R. S. Ruoff, Nano Lett. 9, 4268 (2009).

[30] C. Mattevi, H. Kim, and M. Chhowalla, J. Mater. Chem. 21, 3324 (2011).

[31] P. C. Yang, J. T. Prater, W. Liu, J. T. Glass, and R. F. Davis, J. Electronic Mater. 34, 1558 (2005).

[32] M. Kawasaki, M. Tokuda, and M. Ohtani, Tohoku Daigaku Senko Seiren Kenkyujo Ihou 35, 99 (1980) [in Japanese].

[33] C. Su, A. Lu, C. Wu Y. Li, K. Liu, W. Zhang, S. Lin, Z. Juang, Y. Zhong, F. Chen, and L. Li, Nano Lett. 11, 3612 (2011). 